Gut, 1982, 23, 115-122

\title{
Cell-mediated immunity to gluten within the small intestinal mucosa in coeliac disease*
}

\author{
P D HOWDLE, $\dagger$ A W BULLEN, AND M S LOSOWSKY \\ From the University Department of Medicine, St James's University Hospital, Leeds
}

SUMMARY Jejunal biopsies from controls and coeliac patients were maintained in organ culture in the presence of gluten fraction III. The culture media were assayed for evidence of lymphokine activity in a migration inhibition test using normal peripheral blood leucocytes. Significant inhibition of migration was produced by media from untreated coeliac patients compared with controls $(P<0.005)$ or treated coeliac patients $(P<0.001)$, indicating the production of a leucocyte migration inhibition factor (LIF) by untreated coeliac mucosa in response to gluten fraction III. The degree of inhibition correlated with the preculture interepithelial lymphocyte count in the coeliac biopsies $(\mathrm{P}<0.02)$. In six coeliac patients studied when on a normal diet and on a gluten-free diet, LIF was produced while on a normal diet, but not while on a gluten-free diet. These results suggest that a local cell-mediated immune reaction to gluten is present in the mucosa of patients with untreated coeliac disease but that this is reversed by treatment with a gluten-free diet.

The mechanism by which gluten produces its toxic effect in coeliac disease is unknown. There is, however, considerable evidence of both humoral and cell-mediated immunity to gluten in coeliac patients. ${ }^{1}$ Immunity to gluten may therefore be involved in the production of the characteristic mucosal lesion in coeliac disease. There is much evidence that cell-mediated immunity to gluten may be involved in this pathogenetic process. Ferguson and Murray ${ }^{2}$ showed that untreated coeliac mucosa was abnormally infiltrated with lymphocytes and this has been amply confirmed. There is evidence that interepithelial lymphocytes of the human gastrointestinal tract are $T$ cells. ${ }^{3}$ Leucocyte migration inhibition in coeliac patients in response to various gluten fractions has provided evidence of lymphokine production by peripheral blood lymphocytes. ${ }^{4-7}$ However, more evidence is needed of a cell-mediated mechanism within coeliac mucosa. In a preliminary communication in 1975 , Ferguson et al. ${ }^{8}$ suggested that there are lymphocytes sensitised to $\alpha$-gliadin in untreated but not in treated coeliac mucosa.

\footnotetext{
*This work was presented in part to the British Society of Gastroenterology, Spring Meeting, Hull, 1979.

†Address for reprint requests: Dr P D Howdle, University Department of Medicine, St James's University Hospital, Leeds 9.

Received for publication 25 July 1981
}

We set out to confirm and extend this initial report with regard to treated and untreated patients, and to determine whether treatment with a glutenfree diet could reverse the abnormality in individual patients. The method involves the organ culture of jejunal biopsies in the presence and absence of gluten fraction III and assay of the culture medium for evidence of lymphokine activity.

\section{Methods \\ PATIENTS STUDIED \\ Coeliac patients:}

This group included 15 adult patients with a flat jejunal biopsy; nine have subsequently shown histological response to a gluten-free diet, six have shown a clinical response but have not yet been re-biopsied. These were regarded as untreated coeliac patients.

There were also 23 adult coeliac patients who had all shown a histological improvement after gluten withdrawal which had been continued for at least six months before this study.

One patient who had a normal jejunal biopsy while on a gluten-free diet and who developed symptoms and subtotal villous atrophy when returned to a normal diet was regarded as having coeliac disease. The initial results are included in the treated group, the subsequent results in the untreated group. 
Normal controls

In this group were 18 patients with normal jejunal histology who underwent a biopsy to exclude the diagnosis of coeliac disease. Five were subsequently diagnosed as having irritable bowel syndrome, one had chronic pancreatitis, and the remaining 12 were subsequently shown not to have gastrointestinal disease. Of these 12, eight were being investigated for anaemia, one for recurrent oral ulceration, two for small stature, and one for unexplained weight loss.

\section{Abnormal controls}

This group included three patients with dermatitis herpetiformis who were on a normal diet and had a normal jejunal biopsy, one patient with partial villous atrophy due to tropical sprue, and one with normal jejunal histology but extensive small bowel Crohn's disease beyond the proximal jejunum.

\section{BIOPSIES}

Multiple biopsies were taken with informed consent as part of the routine diagnostic procedure from the region of the ligament of Treitz using the Quinton hydraulic capsule. ${ }^{9}$

\section{CULTURE MEDIUM}

The culture medium consisted of Trowell's T8 medium $(6 \mathrm{ml})$, NCTC 135 medium $(2 \mathrm{ml})$, glutamine $200 \mathrm{mM}(0.2 \mathrm{ml}), 1 \mathrm{M}$ Hepes buffer $(0.1 \mathrm{ml})$ (all obtained from Flow Laboratories Ltd, Ayrshire, Scotland), $1000 \mathrm{U}$ penicillin $(0.1 \mathrm{ml}), 1000 \mathrm{U}$ streptomycin $(0.1 \mathrm{ml})$, and fetal calf serum $(1.5 \mathrm{ml})$ (Wellcome Research Laboratories, Beckenham). ${ }^{8}$ This medium (the 'control medium') was mixed one to two hours before use in the organ culture system, and kept at $37^{\circ} \mathrm{C}$ until the biopsies were obtained.

Gluten-containing medium was similarly constituted with the inclusion of $1 \mathrm{mg} / \mathrm{ml}$ of gluten fraction III (GFIII) ${ }^{10}$ prepared from gluten (BDH Chemical Co. Ltd, Poole, UK).

Casein-containing medium was constituted by the inclusion in control medium of $1 \mathrm{mg} / \mathrm{ml}$ of a peptic-tryptic digest of casein (BDH Chemical Co. Ltd), prepared in a similar way to GFIII. ${ }^{10}$

\section{CULTURE PROCEDURE}

The biopsies, delivered by the Quinton biopsy apparatus into Ringer-Tyrode solution, were immediately placed in ice-cold control medium and cut into two or three pieces. The pieces were mounted villous surface uppermost on the wire grid of a sterile organ culture dish (Falcon Plastics Ltd, Los Angeles, California), and the central well was filled with approximately $1 \mathrm{ml}$ of culture medium so as just to touch the under-surface of the biopsy. The time from excision of biopsy to its being in position in the dish was approximately five minutes. The outer ring of the culture dish contained absorbent paper which was saturated in $0.9 \% \mathrm{NaCl}$ solution.

The dishes were placed in a sterile anaerobic jar, which was gassed with $95 \% \mathrm{O}_{2}: 5 \% \mathrm{CO}_{2}$ for 30 minutes, then sealed and kept in an incubator at $37^{\circ} \mathrm{C}$.

In all patients and controls two pieces of biopsy were cultured in control medium and two pieces in gluten-containing medium. In three untreated and three treated coeliac patients two more pieces were cultured in control medium and two in caseincontaining medium.

After five hours of culture the media were removed from the central wells, transferred to sterile containers and stored at $-70^{\circ} \mathrm{C}$ for later assessment of lymphokine activity.

Further culture of the jejunal biopsies was continued in freshly prepared replacement media and after 24 hours' culture good preservation of the tissue was observed, similar to that previously described by us. ${ }^{11}$

\section{ASSESSMENT OF LYMPHOKINE ACTIVITY BY MIGRATION INHIBITION}

Leucocyte migration inhibition tests were performed on normal peripheral blood leucocytes from one of us. These leucocytes had previously been shown not to be inhibited by $1 \mathrm{mg} / \mathrm{ml}$ of GFIII.

Twenty millilitres of peripheral venous blood were defibrinated by shaking with glass beads and mixed with $10 \mathrm{ml}$ dextran 150 in $0.9 \%$ saline under sterile conditions. After sedimentation for $\mathbf{3 0}$ minutes the leucocyte-rich supernate was centrifuged for 10 minutes at $1000 \mathrm{rpm}$. The cell pellet was resuspended in $10 \mathrm{ml}$ medium 199 and recentrifuged for another 10 minutes at $1000 \mathrm{rpm}$. This washing procedure was repeated three times. The cell pellet was resuspended in medium 199 to give a packed cell volume of about $50 \%$. The suspension was drawn into $20 \mu$ capillary tubes (Drummond microcaps), which were heat sealed at one end, taking care not to char the cells. The cells were packed by centrifugation at $500 \mathrm{rpm}$ for five minutes. Each capillary tube was cut squarely across just below the cell fluid interface and secured by silicone grease in Sterilin migration chambers which were rimmed with silicon grease. The chambers were filled with the organ culture medium, sealed with a coverslip, and incubated at $37^{\circ} \mathrm{C}$ for 20 hours.

Migration chambers were set up in quadruplicate and contained gluten-containing medium which 
had been used for organ culture, or control medium from the same patient which had been used for organ culture and then reconstituted with $1 \mathrm{mg} / \mathrm{ml}$ of GFIII. In six coeliac patients chambers were set up using the casein-containing medium or control medium reconstituted with casein.

After incubation the image of each migration chamber was projected on to a screen at constant magnification and the migration areas were traced out and measured by planimetry.

The migration index was calculated for each patient as the mean area of migration in gluten- (or casein) containing medium divided by the mean area of migration in control medium reconstituted with gluten (or casein) after culture.

The concentration of $1 \mathrm{mg} / \mathrm{ml}$ of GFIII used in these experiments was chosen, as we have previously shown that peripheral blood leucocytes from coeliac patients are sensitised to this concentration ${ }^{4}$ and also that coeliac mucosa shows in vitro sensitivity to this concentration. ${ }^{11}$

INTER-EPITHELIAL LYMPHOCYTE COUNTS

These were performed on biopsies from all subjects obtained at the same time as those for organ culture but sent for routine histology. They were counted 'blind' by the method of Ferguson and Murray. ${ }^{2}$ At least 500 epithelial cells were counted and results expressed as the number of lymphocytes per 100 epithelial cells.

HL-A TYPING

The HL-A status of the patients was determined by a modification of the micro-lymphocytotoxic technique of Terasaki and McClelland. ${ }^{12}$

\section{STATISTICS}

Paired, non-paired $t$ tests, correlation coefficient, and test of skewness ${ }^{13}$ were used in the statistical analysis.

\section{Results}

Migration indices for the three groups of patients are shown in Fig. 1 and Table 1. The results are not significantly skewed and therefore parametric statistics were used to compare the data. The $95 \%$ confidence limits (mean $\pm 2 S D$ ) were calculated for the control group and migration indices below $2 \mathrm{SD}$ of the mean control value were taken to indicate significant inhibition.

In the 18 control patients there was no inhibition of leucocyte migration as the mean migration index was 1.009. There was no significant difference between treated coeliac patients and controls, the mean migration index in treated coeliac patients

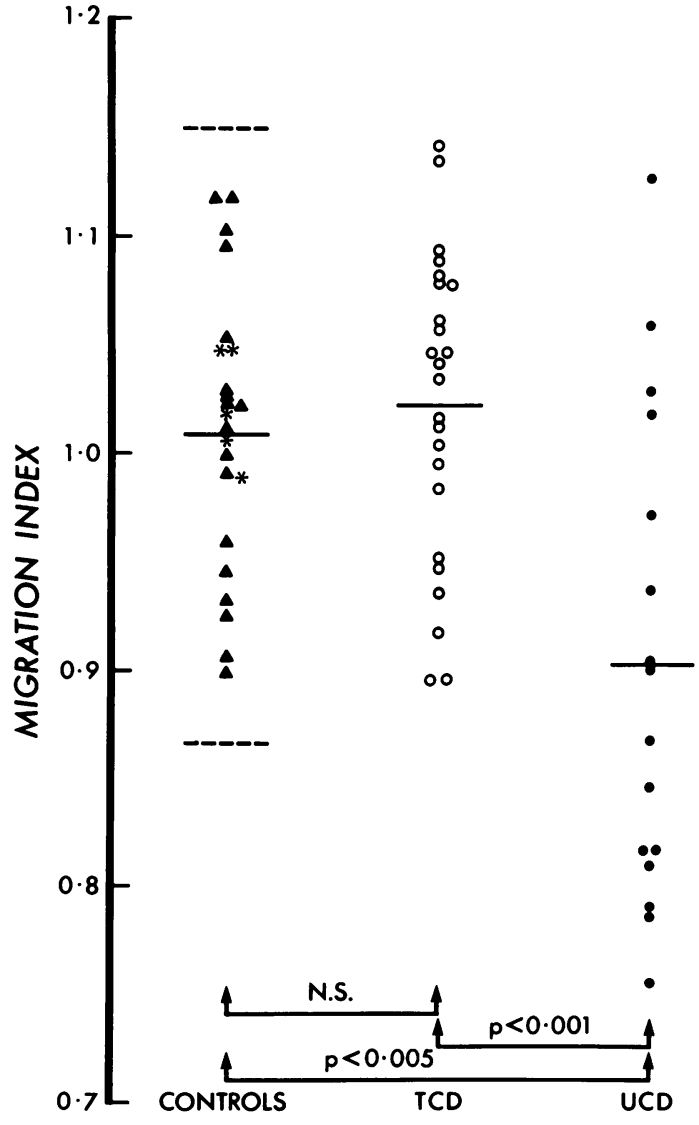

Fig. 1 Migration indices in controls $(\mathbf{\Delta})$, and patients with treated (TCD O) and untreated coeliac disease (UCD ). Broken lines indicate 2 standard deviations above and below the mean of the controls. *Abnormal controls.

being 1.023 , and all indices in treated coeliac patients fell within the $95 \%$ confidence limits of the control patients.

There was significant inhibition in the untreated coeliac patients compared with controls $(P<0.005)$ or treated coeliac patients $(P<0.001)$. The mean migration index for untreated coeliac patients was 0.903 and seven patients $(44 \%)$ showed indices below the 2 SD limit of the controls.

In Fig. 1 and Table 1 are contained the results from the three dermatitis herpetiformis patients, none of whom showed migration inhibition, and also from the Crohn's disease and tropical sprue patients, neither of whom showed inhibition.

HL-A typing was available in all coeliac patients and in 11 of the 18 normal control subjects. Migration indices were compared between B8 positive and B8 negative subjects within each group. The three dermatitis herpetiformis patients 
Table 1 Migration indices (MI), HLA B8 status, and interepithelial lymphocyte counts (IEL) in three groups of patients

\begin{tabular}{|c|c|c|c|c|c|c|c|c|c|c|c|}
\hline \multicolumn{4}{|l|}{ Controls } & \multicolumn{4}{|c|}{ Treated coeliac disease } & \multicolumn{4}{|c|}{ Untreated coeliac disease } \\
\hline Patient & $M I$ & $H L A B 8$ & IEL & Patient & $M I$ & $H L A B 8$ & $I E L$ & Patient & $M I$ & $H L A B 8$ & $I E L$ \\
\hline $\begin{array}{l}1 \\
2 \\
3 \\
4 \\
5 \\
6 \\
7 \\
8 \\
9 \\
10 \\
11 \\
12 \\
13 \\
14 \\
15 \\
16 \\
17 \\
18 \\
\text { Mean } \\
+2 \text { SD } \\
\text { Dermatitis } \\
\text { herpetiform } \\
1 \\
2 \\
3 \\
\text { Crohn's } \\
\text { disease } \\
\text { Tropical } \\
\text { sprue }\end{array}$ & $\begin{array}{l}0.9061 \\
0.899 \\
0.925 \\
1.054 \\
0.946 \\
0.932 \\
0.959 \\
1.012 \\
1.103 \\
1.000 \\
1.024 \\
1.029 \\
1.118 \\
1.118 \\
1.027 \\
1.023 \\
0.990 \\
1.096 \\
1.009 \\
0.142 \\
\\
\text { nis patients } \\
0.989 \\
1.019 \\
1.006 \\
1.048 \\
1.048\end{array}$ & $\begin{array}{l}\text { NA } \\
- \\
+ \\
\text { NA } \\
\text { NA } \\
- \\
\text { - } \\
\text { NA } \\
\text { NA } \\
\text { NA } \\
\text { NA } \\
\text { - } \\
+ \\
\overline{+} \\
\\
\text { s } \\
+ \\
\overline{+} \\
+\end{array}$ & $\begin{array}{r}14.24 \\
12.99 \\
20.77 \\
16.28 \\
17.65 \\
20.77 \\
12.11 \\
16.51 \\
19.52 \\
10.50 \\
9.89 \\
12.57 \\
12.87 \\
12.99 \\
13.89 \\
15.74 \\
12.99 \\
16.96 \\
14.96 \\
6.53\end{array}$ & $\begin{array}{l}1 \\
2 \\
3 \\
4 \\
5 \\
6 \\
7 \\
8 \\
9 \\
10 \\
11 \\
12 \\
13 \\
14 \\
15 \\
16 \\
17 \\
18 \\
19 \\
20 \\
21 \\
22 \\
23 \\
24 \\
\text { Mean }\end{array}$ & $\begin{array}{l}1.005 \\
1.080 \\
0.985 \\
1.079 \\
1.090 \\
1.035 \\
1.143 \\
1.136 \\
1.042 \\
0.948 \\
0.896 \\
1.013 \\
0.936 \\
1.058 \\
0.996 \\
0.896 \\
0.918 \\
1.062 \\
1.047 \\
1.095 \\
1.017 \\
1.047 \\
1.083 \\
0.953 \\
1.023\end{array}$ & $\begin{array}{l}+ \\
+ \\
+ \\
+ \\
+ \\
+ \\
+ \\
- \\
+ \\
+ \\
+ \\
+ \\
+ \\
+ \\
+ \\
- \\
+ \\
+ \\
+ \\
+ \\
- \\
+ \\
+ \\
+\end{array}$ & 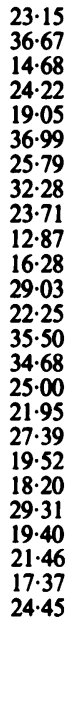 & $\begin{array}{c}1 \\
2 \\
3 \\
4 \\
5 \\
6 \\
7 \\
8 \\
9 \\
10 \\
11 \\
12 \\
13 \\
14 \\
15 \\
16 \\
\text { Mean }\end{array}$ & $\begin{array}{l}0.817 \\
0.938 \\
0.868 \\
0.973 \\
1.030 \\
0.792 \\
0.810 \\
0.817 \\
1.128 \\
1.060 \\
0.901 \\
0.847 \\
0.756 \\
0.904 \\
1.019 \\
0.786 \\
0.903\end{array}$ & $\begin{array}{l}+ \\
- \\
+ \\
+ \\
- \\
+ \\
+ \\
- \\
+ \\
+ \\
+ \\
+ \\
+ \\
+ \\
+ \\
+\end{array}$ & $\begin{array}{l}52.67 \\
45.14 \\
49.25 \\
46.44 \\
47.33 \\
46.52 \\
45.63 \\
76.32 \\
52.09 \\
56.86 \\
55.44 \\
68.54 \\
42.86 \\
37.61 \\
52.76 \\
36.99 \\
50.77\end{array}$ \\
\hline
\end{tabular}

were included with the 11 normal controls because of the small number of $\mathrm{B} 8$ positive patients in the normal control group. There was no difference in any group between migration indices in $\mathrm{B} 8$ positive and negative patients.

In three untreated coeliac patients and three treated coeliac patients migration indices were available from media where casein had been used as the antigen instead of gluten. The results are shown in Table 2. In untreated coeliac patient no. 1, there was significant inhibition with GFIII but not casein; in the other two there was no inhibition with either antigen. Similarly, with the three treated coeliac patients, there was no inhibition with either antigen.

Interepithelial lymphocyte counts are shown in Fig. 2 and Table 1 . The counts are not significantly skewed and parametric statistics were used for comparison. The $95 \%$ confidence limits (mean \pm $2 \mathrm{SD}$ ) in the controls were used to define the normal range in these patients.

There were significant differences in interepithelial lymphocyte counts between controls and both untreated and treated coeliac patients $(P<0.001)$ and also between untreated and treated coeliac patients $(P<0.001)$. There was no overlap between the control limits and those of the untreated coeliac patients. The range of controls was similar to that described by other authors. ${ }^{14}$
Table 2 Migration indices in untreated and treated coeliac patients with gluten or casein as antigen

\begin{tabular}{lll}
\hline & + Gluten & + Casein \\
\hline Untreated & & \\
1 & 0.817 & 1.077 \\
2 & 1.128 & 0.980 \\
3 & 1.060 & 0.950 \\
Treated & 1.058 & 1.147 \\
1 & 0.996 & 0.985 \\
2 & 1.095 & 1.070 \\
3 & & \\
\hline
\end{tabular}

Values from the abnormal controls were not included in the statistical calculations. As can be seen from Table 1, the interepithelial lymphocyte count was raised in both the Crohn's patient and the patient with tropical sprue, but normal in all three patients with dermatitis herpetiformis.

The migration index was correlated with the preculture interepithelial lymphocyte count in all the coeliac patients (Fig. 3). There was a low negative correlation $(\mathrm{r}=-0.40)$ which was, however, statistically significant $(\mathrm{P}<0.02)$.

Six of the coeliac patients were included in both untreated and treated coeliac groups, and thus paired data were available for these patients while taking a normal and also a gluten-free diet. The patient who initially had normal histology on a 


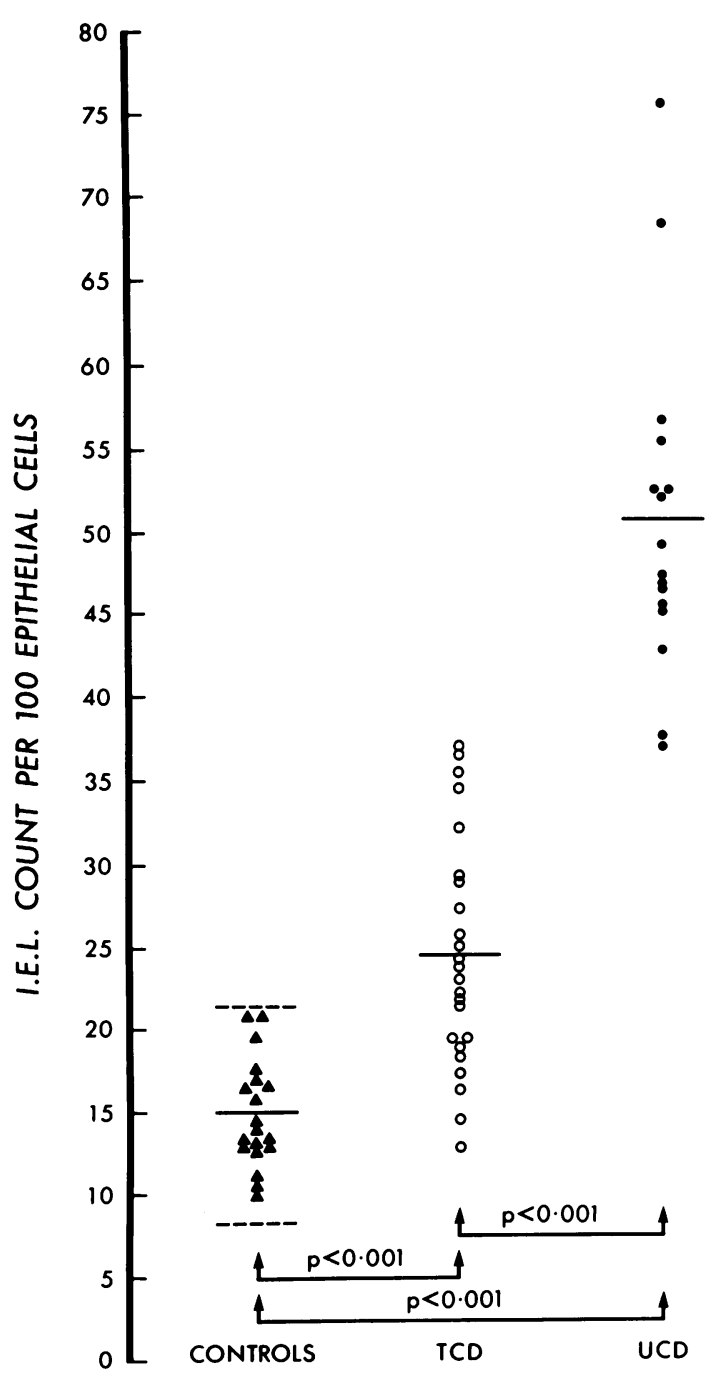

Fig. 2 Interepithelial lymphocyte (IEL) counts in controls $(\triangle)$, and patients with treated (TCD O) and untreated coeliac disease (UCD ९). Broken lines indicate 2 standard deviations above and below the mean of the controls.

gluten-free diet and who developed subtotal villous atrophy on a normal diet is included in these paired results. The results of the migration indices are shown in Fig. 4. There is a significant increase in migration indices on a gluten-free diet compared with a normal diet $(P<0.05)$. In five patients, the migration index increased when the patient was on a gluten-free diet. In four of these patients there was significant inhibition on a normal diet which returned to the normal range on a gluten-free diet.
The fifth patient was the one who developed abnormal histology after a normal diet for one month; the migration index was initially 0.936 and this decreased to 0.901 on a normal diet and might have decreased more if the patient had not then returned to a gluten-free diet. In one patient there was an initial migration index within the normal range. This fell on a gluten-free diet but still remained within the normal range.

Figure 5 shows the interepithelial lymphocyte counts in biopsies from these same patients, taken while on a normal and a gluten-free diet. In every case the interepithelial lymphocyte count fell while on a gluten-free diet. This fall was significant $(\mathrm{P}<0.001)$; the mean interepithelial lymphocyte count fell from 52.04 to 21.23 (within the normal range).

\section{Discussion}

This report confirms the findings in the preliminary communication of Ferguson et al. ${ }^{8}$ The results show that a substance is produced by untreated coeliac mucosa in the presence of GFIII, which inhibits the migration of normal peripheral blood leucocytes, and that this abnormality can be reversed by treatment with a gluten-free diet. The inhibition of migration of peripheral blood leucocytes is generally taken to be an in vitro correlate of cell-mediated immunity. The substance producing migration inhibition is thought to be a lymphokine, leucocyte migration inhibitory factor (LIF), which is produced by sensitised lymphocytes on contact with their specific antigen. In the system used in this series of experiments it is believed that the lymphocytes sensitised to gluten are present in the coeliac mucosa and it is postulated that on exposure to GFIII in the organ culture system they release LIF into the culture medium. The presence of this LIF can then be assayed by its effect on the migration of normal leucocytes from capillary tubes.

As expected, there was no LIF produced by any of the controls. Nor was it produced in the three patients with dermatitis herpetiformis, although this was not unexpected, as they had no evidence of in vivo gluten sensitivity; their jejunal biopsies were normal and the interepithelial lymphocyte counts were within the normal range. The patients with Crohn's disease and tropical sprue did not produce LIF, even though their interepithelial lymphocyte counts were raised and there was partial villous atrophy in the patient with tropical sprue, suggesting that abnormal mucosa in other diseases is not sensitised to gluten.

An inhibitory factor was produced by the untreated coeliac mucosa in the presence of GFIII. 


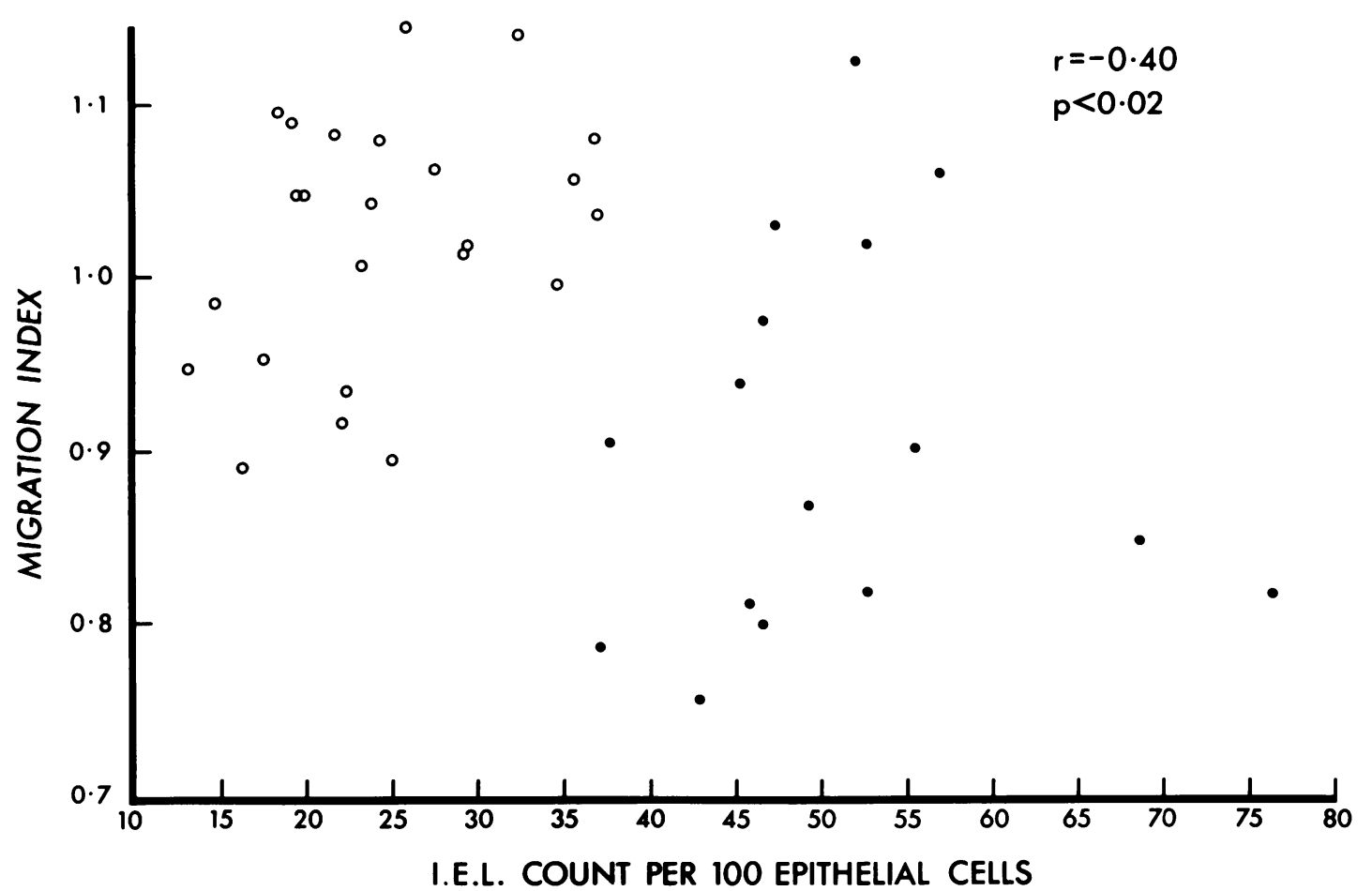

Fig. 3 Migration indices and interepithelial lymphocyte (IEL) counts in treated (O) and untreated (O) coeliac patients.

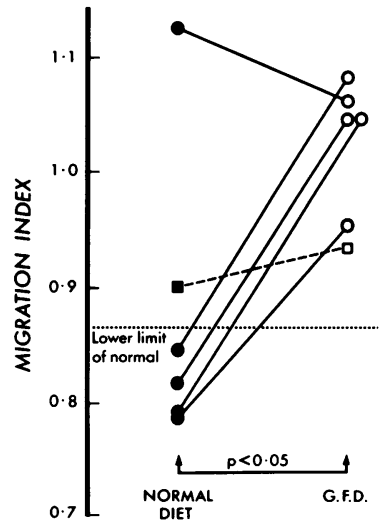

Fig. 4 Migration indices in six coeliac patients while on a normal (O) and on a gluten-free diet (GFD O). The dotted line represents 2 standard deviations below the control mean. The patient marked $\square--\square$ was initially on a gluten-free diet and developed subtotal villous atrophy on a normal diet.

There is support for the specificity of gluten as the antigen, as casein did not stimulate the production of LIF in three untreated coeliac mucosae. However, it must be noted that, unfortunately, in only one of these three particular untreated coeliac

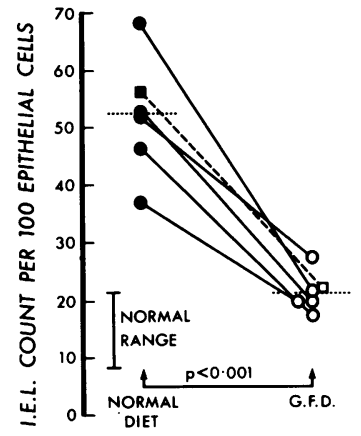

Fig 5 Interepithelial lymphocyte (IEL) counts in six coeliac patients while on a normal and gluten-free diet (GFD). Symbols as in Fig. 4. Dotted lines indicate means, normal range as in Fig. 2.

mucosae did gluten stimulate the production of LIF.

If this inhibitory factor is produced by sensitised lymphocytes one might expect that there would be some correlation between the degree of inhibitionthat is, amount of LIF produced-and the interepithelial lymphocyte count. The results show that there is a significant correlation between these two 
parameters, although it is quite low. This weakness of the correlation is not unexpected, as there are presumably lymphocytes sensitised to gluten elsewhere in the mucosa besides the epithelium. There is also the patchiness of the coeliac mucosal lesion to consider, ${ }^{15}$ giving rise to the possibility that the biopsy on which the interepithelial lymphocyte count is made is affected to a different degree from that which is cultured to produce the LIF. It should also be noted that there are inherent technical difficulties in both the organ culture and leucocyte migration techniques, which give rise to the possibility that experimental variation could reduce any correlation.

The results show that, after treatment with a gluten-free diet, LIF is not produced in coeliac patients; in none of the treated patients was an LIF produced in the presence of gluten, nor, incidentally, in three patients in the presence of casein. Moreover, the change produced by a gluten-free diet is shown more specifically in the six patients who were studied on a normal and on a gluten-free diet. In five of these, inhibition on a normal diet was reversed by a gluten-free diet; in the sixth patient there was no inhibition on either diet. In these six patients it can also be seen that the interepithelial lymphocyte counts fell towards the normal range on a gluten-free diet.

Although the production of an LIF and the interepithelial lymphocyte count correlate, this is not evidence that they are causally related. The decrease in the LIF production and the fall in the interepithelial lymphocyte count on a gluten-free diet may both probably reflect the reversal of the underlying pathogenetic mechanism in coeliac disease in response to gluten withdrawal.

The HL-A B8 status of these patients was studied in relation to the migration index. There is some evidence that the in vitro sensitivity of untreated coeliac mucosa to gluten is dependent upon the presence of the B8 antigen, ${ }^{16}$ although we have not confirmed this. ${ }^{11}{ }^{17}$ There is also some evidence that the peripheral blood leucocytes of normal controls are more sensitive to gluten if they are from an HL-A B8 positive donor than a non-B8 donor. ${ }^{6}$ However, there was no difference in any group of patients between migration indices in $\mathrm{B} 8$ positive or negative patients. This finding would be in keeping with our previous results that the in vitro gluten sensitivity of a mucosal biopsy is not enhanced by the possession of the B8 antigen. ${ }^{11} 17$

We have interpreted our results in these experiments in terms of a cell-mediated immune reaction to gluten within untreated coeliac mucosa. It is important to note, however, that other explanations are possible. Leucocyte migration has been shown to be inhibited by a number of biologically derived materials other than lymphokines. In 1969 Spitler et al. ${ }^{18}$ demonstrated that capillary migration of peritoneal exudate cells was inhibited by antigen-antibody complexes; this was confirmed by Kotkes and Pick in $1975 .{ }^{19}$ Migration inhibition has also been shown to be mediated by antibody ${ }^{20}$ and Bice et al. ${ }^{21}$ showed that macrophage migration was inhibited by a plasma factor from patients with neoplasms and normal individuals, this factor resembling $\alpha-2$-macroglobulin. These reports are relevant to the present experiments, as Falchuk et al. 22 demonstrated the secretion of a humoral factor by untreated coeliac mucosa during organ culture in the presence of gluten peptides. They proposed that this humoral factor was principally anti-gluten antibody which was complexing with gluten or the enterocyte cell surface. On this basis, gluten-antigluten complexes could cause migration inhibition and therefore explain the present findings. Another explanation is that inhibition of migration could be due to the presence of cytophilic antibody coating macrophages or monocytes. ${ }^{120}$

One way to answer this question in part would be to try to prevent lymphokine production by including a protein synthesis inhibitor in this system. Such an inhibitor is puromycin, which is well demonstrated as inhibiting lymphokine synthesis. ${ }^{23-25}$ We have such experiments under way to try to answer this question.

One final problem is that lymphokines are assumed to be products of T-lymphocytes, but there is evidence that migration inhibition factors can be produced by fibroblast cell culture lines ${ }^{26}$ or by both T- and B-lymphocytes. ${ }^{27}$

It is apparent, therefore, that, despite our assumption that the results in this paper suggest that sensitised lymphocytes within untreated coeliac mucosa produce a leucocyte migration inhibition factor in the presence of GFIII and support the proposal that a cell-mediated immune reaction may be involved in the production of the mucosal lesion in coeliac disease, other explanations are possible.

We are grateful to Dr S M Rajah, Regional Blood Transfusion Laboratory, Leeds, for performing the HLA typing.

\section{References}

1 Asquith P, Haeney MR. Coeliac disease. In: Asquith P, ed. Immunology of the gastrointestinal tract. Edinburgh: Churchill Livingstone, 1979.

2 Ferguson A, Murray D. Quantitation of intraepithelial lymphocytes in human jejunum. Gut 1971; 12:988-94.

3 Selby WS, Janossy G, Jewell DP. Immunohistological 
characterisation of intraepithelial lymphocytes of the human gastrointestinal tract. Gut 1981; 22:169-76.

4 Bullen AW, Losowsky MS. Cell-mediated immunity to gluten fraction III in adult coeliac disease. Gut 1978; 19:126-31.

5 Haeney MR, Asquith P. Inhibition of leucocyte migration by $\alpha$-gliadin in patients with gastrointestinal disease: its specificity with respect to $\alpha$-gliadin and coeliac disease. In: McNicholl B, McCarthy CF, Fottrell PF, eds. Perspectives in coeliac disease. Lancaster: MTP Press, 1978.

6 Simpson FG, Bullen AW, Robertson DAF, Losowsky MS. HLA-B8 and cellular immune response to gluten. Gut 1981; 22:633-6.

7 O'Farrelly C, Feighery C, Greally JF, Weir DG. Improved technique for the detection of alpha gliadin sensitised cells in the peripheral blood of untreated coeliac patients. Gut 1981; 22:A421.

8 Ferguson A, MacDonald TT, McClure JP, Holden RJ. Cell-mediated immunity to gliadin within the smallintestinal mucosa in coeliac disease. Lancet 1975; 1: 895-7.

9 Scott BB, Losowsky MS. Peroral small-intestinal biopsy: experience with the hydraulic multiple biopsy instrument in routine clinical practice. Gut 1976; 17: 740-3.

10 Frazer AC, Fletcher RF, Ross CAC, Shaw B, Sammons HG, Schneider R. Gluten-induced enteropathy. The effect of partially digested gluten. Lancet 1959; II:252-5.

11 Howdle PD, Corazza GR, Bullen AW, Losowsky MS. Gluten sensitivity of small intestinal mucosa in vitro: quantitative assessment of histologic change. Gastroenterology 1981; 80:442-50.

12 Terasaki PI, McClelland JD. Microdroplet assay of human serum cytotoxins. Nature $1964 ; 204: 998-1000$.

13 Snedecor GW, Cochran WG. Statistical methods. Ames, Iowa State University Press, 1967.

14 Ferguson A. Progress report: Intraepithelial lymphocytes of the small intestine. Gut 1977; 18:921-37.

15 Scott BB, Losowsky MS. Patchiness and duodenaljejunal variation of the mucosal abnormality in coeliac disease and dermatitis herpetiformis. Gut 1976; 17: 984-92.
16 Falchuk ZM, Nelson DA, Katz AJ et al. Glutensensitive enteropathy. Influence of histo-compatibility type on gluten sensitivity in vitro. $J$ Clin Invest 1980; 66:227-33.

17 Howdle PD, Corazza GR, Bullen AW, Losowsky MS. In vitro diagnosis of coeliac disease-an assessment. Gut 1981; 22:939-47.

18 Spitler L, Huber H, Fudenberg HH. Inhibition of capillary migration by antigen-antibody complexes. $J$ Immunol 1969; 102:404-11.

19 Kotkes P, Pick E. Studies on the inhibition of macrophage migration induced by soluble antigen-antibody complexes. Clin Exp Immunol 1975; 19:105-20.

20 Brostoff $J$. Critique of present in vitro methods for the detection of cell-mediated immunity. Proc Roy Soc Med 1974; 67:514-6.

21 Bice DE, Gruwell D, Salvaggio J. Inhibition of macrophage migration by plasma factor(s) from patients with neoplasms and normal individuals. $J$ Reticuloendothel Soc 1976; 19:281-9.

22 Falchuk ZM, Gebhard RL, Strober W. The pathogenesis of gluten sensitive enteropathy (celiac sprue): organ culture studies. In: Hekkens WThJM, Pena AS, eds. Coeliac disease: proceedings of the second international coeliac symposium. Leiden; Stenfert Kroese, 1975.

23 David JR. Suppression of delayed hypersensitivity in vitro by inhibition of protein synthesis. J Exp Med 1965; 122:1125-34.

24 Maini RN, Roffe LM, Magrath JT; Dumonde DC. Standardization of the leucocyte migration test. Int Arch Allergy 1973; 45:308-21.

25 Mitchell CG, Smith MGM, Golding PL, Eddleston ALWF, Williams R. Evaluation of the leucocyte migration test as a measure of delayed hypersensitivity in man. Suppression of migration inhibition by puromycin. Clin Exp Immunol 1972; 11:535-41.

26 Tubergen DG, Feldman JD, Pollock EM, Lerner RA. Production of macrophage migration inhibition factor by continuous cell lines. J Exp Med 1972; 135:255-66.

27 Rocklin RE, MacDermott RP, Chess L, Schlossman SF, David JR. Studies on mediator production by highly purified human T and B lymphocytes. J Exp Med 1974; 140:1303-16. 